products, the gas ${ }^{10} \mathrm{Ar}$, in low concentrations. It is more difficult to date more recent ages than older ones because of the small quantities of argon involved, and the lower limit of the method is at present half a million years or a little less.

At the other end of the scale is radiocarbon dating. Radiocarbon dates now provide the essential basis for prehistoric chronology from Upper Palaeolithic times on and, until recently, radiocarbon seemed the most reliable of radioactive clocks. For a radioactivitybased age determination, it is usually necessary, of course, both to measure the quantity of the decay product present and the quantity left of the parent isotope. Radiocarbon dating was able to dispense with the former, because the original concentration of the parent isotope, ${ }^{14} \mathrm{C}$, was assumed to be the same as the modern atmospheric concentration. The discovery that the atmospheric concentration of ${ }^{14} \mathrm{C}$ has fluctuated in recent millennia by up to 8 per cent of the present level has come therefore as something of a shock. The radiocarbon determination of dendrochronologically dated samples is now allowing the investigation of this effect back to $6000 \mathrm{BC}$, but its magnitude before this time remains uncertain.

The half-life of radiocarbon, approximately $5.7 \times 10^{3} \mathrm{yr}$, sets a more fundamental limitation on the age of samples which can be dated. The short halflife means that after a few tens of millennia there is very little radioactivity left in the specimen, and the counting of disintegrations in the sample is always complicated by a background activity caused by cosmic radiation which cannot be eliminated. Even the isotopic enrichment of gas samples only increases the effective time range of the method to a maximum of $70,000 \mathrm{yr}$.

Between the potassium-argon and radiocarbon dating methods lies a gap from 50,000 to $500,000 \mathrm{yr}$ where other methods are required. Fission track dating is a possibility, especially when applied to volcanic glass. But like the potassium-argon method it gives the date of formation of the rocks under examination so that for more recent times, where the archaeological remains are not likely to be interstratified with eruptive deposits, this is a serious limitation. It is over this time range that thermoluminescence dating would be most useful.

Thermoluminescence dating depends on the principle that many minerals give off light when heated-the light emitted being proportional to the radiation dose experienced since the formation of the material. Archaeologically it has so far been principally applied to pottery and baked clay and the dating involves determining the radiogenic minerals in the clay as well as the thermolumin- escence itself. The necessity of determining very small quantities of decay product (as in the potassium-argon method) or of the parent isotope (as in the radiocarbon method) is thus avoided. An early problem was how to eliminate light during the readout on heating, which derived from the energy used in pulverizing the sample. Fortunately, heating in an atmosphere of nitrogen considerably reduces this problem. Further improvement of this method came from the separation of different grain sizes in the pottery and an accuracy of less than 10 per cent is claimed for fine grain dating (Zimmerman, Archaeometry, 13, 29; 1971).

Until recently the chief application of thermoluminescence dating has been in testing the authenticity of museum objects. The magnitude of the variations in atmospheric concentration of ${ }^{14} \mathrm{C}$, suggested by tree-ring work, indicated a further useful line of approach, and the first TL results of Zimmerman and Huxtable on early neolithic pottery from the Balkans (Antiquity, 44, 304; 1970) lend some support to the long chronology indicated by tree-ring work. Pottery was unfortunately not manufactured before about $7000 \mathrm{BC}$, but the

\section{Mechanism of Polarity in Dispute}

THE mechanism of genetic polarity has of late become the centre of one of those controversies which occasionally enliven the literature and the coffee room. One camp holds that nonsense codons, by stopping the movement of ribosomes translating nascent messenger RNA molecules, prevent further transcription because transcription is coupled to translation. Members of the other camp argue, however, that nascent messenger RNA chains continue to be elongated after a nonsense codon at some early position has prevented ribosomes translating the messenger. They claim that because the newly made stretches of messenger are devoid of ribosomes they are rendered susceptible to attack by nucleases and are degraded.

In next Wednesday's Nature New Biology there are two articles which present conflicting data to succour members of both camps. Imamoto and Kano, who favour the first hypothesis, have studied the synthesis of tryp operon mRNA in a strain of Escherichia coli with a temperature sensitive mutation in the structural gene for one of the 30 S ribosome proteins, P10, which must be present for ribosomes to initiate translation of natural messengers. They present evidence which suggests that the overall rate of transcription of the $t r v p$ operon in this strain parallels the rate of protein synthesis. At the nonpermissive temperature protein same authors have dated baked clay figurines from the Gravettian site of Dolni Vestonice to 33,000 BP (Archaeometry, 13, 57; 1971). The thermoluminescence age is 15 per cent higher than the radiocarbon age. with a probable error of 10 per cent. The method thus offers a useful check on radiocarbon dates.

The materials most readily available from Palaeolithic deposits are flint and bone, and it is these which make the work reported by Christodoulides and Fremlin, and the work which is currently in progress on thermoluminescence dating of flint, so promising. Once again the chief problem is luminescence arising independently of the radiogenic thermoluminescence which is to be measured. Christodoulides and Fremlin have reduced this effect to the extent that useful measurements can now be made on samples older than $100,000 \mathrm{yr}$.

If further work succeeds in reducing this background thermoluminescence by another order of magnitude, the method may yet yield useful dates in, and beyond, the 8,000 to $50,000 \mathrm{yr}$ range at present covered by radiocarbon dating. but not yet checked by dendro. chronology. synthesis is impaired and correlated with this synthesis of tryp messenger RNA is arrested.

By contrast, a few weeks ago Morse and his colleagues reported in Nature New Biology $(231,214 ; 1971)$ experiments which suggest that messengers devoid of ribosomes are degraded by a previously undetected endonuclease. Morse and Guertin now report new experiments on the effect of starving $E$. coli of amino-acids on the polarity of polar nonsense mutations in the tryp operon. Polarity is relieved when stringent cells carrying such mutations are starved; in other words, the tryp mRNA distal to the polar nonsense mutation, which is rapidly degraded in the presence of an adequate supply of amino-acids is stabilized when aminoacids are in short supply. By contrast. when relaxed strains are similarly starved there is no relief of polarity: indeed polarity is enhanced.

Morse and Guertin suggest that because starvation of stringent cells re sults in the cessation of ribosomal RNA synthesis as well as protein synthesis nucleotides must accumulate. and this might well result, by some feedback control mechanism, in the inactivation of nucleases. Messengers although exposed might therefore survive. By contrast, when relaxed cells are starved ribosomal RNA synthesis continues even though protein synthesis is halted. 